\title{
BMJ Open Multicentre, non-interventional study of the efficacy and tolerability of linaclotide in the treatment of irritable bowel syndrome with constipation in primary, secondary and tertiary centres: the Alpine study
}

To cite: Pohl D, Fried M, Lawrance D, et al. Multicentre, non-interventional study of the efficacy and tolerability of linaclotide in the treatment of irritable bowel syndrome with constipation in primary, secondary and tertiary centres: the Alpine study. BMJ Open 2019;9:e025627. doi:10.1136/ bmjopen-2018-025627

- Prepublication history for this paper is available online. To view these files, please visit the journal online (http://dx.doi. org/10.1136/bmjopen-2018025627).

Received 14 August 2018 Revised 03 December 2019 Accepted 04 December 2019

Check for updates

(c) Author(s) (or their employer(s)) 2019. Re-use permitted under CC BY-NC. No commercial re-use. See rights and permissions. Published by BMJ.

For numbered affiliations see end of article.

Correspondence to

Professor Heinz F. Hammer;

heinz.hammer@medunigraz.at

\section{ABSTRACT}

Objectives We evaluated the effectiveness and tolerability of linaclotide, a minimally absorbed guanylate cyclase-C agonist, in patients with irritable bowel syndrome with constipation (IBS-C) in routine clinical practice.

Setting A multicentre, non-interventional study conducted between December 2013 and November 2015 across 31 primary, secondary and tertiary centres in Austria and Switzerland.

Participants The study enrolled 138 patients aged $\geq 18$ years with moderate-to-severe IBS-C. Treatment decision was at the physician's discretion. Patients with known hypersensitivity to the study drug or suspected mechanical obstruction were excluded. The mean age of participants was 50 years, and $>75 \%$ of the patients were women. 128 patients completed the study.

Primary and secondary outcome measures Data were collected at weeks 0 and 4 in Austria and weeks 0, 4 and 16 in Switzerland. The primary effectiveness endpoints included severity of abdominal pain and bloating (11-point numerical rating scale $[0=$ no pain/bloating to $10=$ worst possible pain/bloating]), frequency of bowel movements and physicians' global effectiveness of linaclotide. Treatment-related adverse events (AEs) were recorded. Results Following a 4-week treatment period, the mean intensity score of abdominal pain was reduced from 5.8 at baseline to 2.7 , while the bloating intensity score was reduced from 5.8 at baseline to $3.1 \mathrm{e}$ (both indices $p<0.001$ ). The frequency of mean weekly bowel movements increased from 2.1 at baseline to 4.5 at week 4 ( $p<0.001)$. Global effectiveness and tolerability of linaclotide were assessed by the treating physicians as 'good' or 'excellent' in $>70 \%$ of patients. In total, 31 AEs were reported in 22 patients, the most common being diarrhoea, reported by $6(7 \%)$ and $8(15.4 \%)$ patients in Austria and Switzerland, respectively.

Conclusions Patients with IBS-C receiving linaclotide experienced effective treatment of moderate-to-severe symptoms in routine clinical practice. Linaclotide was safe and well tolerated and no new safety concerns were raised, supporting results from previous clinical trials.
Strengths and limitations of this study

- This is the first real-world study evaluating the effectiveness and tolerability of an irritable bowel syndrome with constipation treatment in the Alpine region.

- This study sought to evaluate whether the efficacy and tolerability of linaclotide that was demonstrated in randomised clinical trials could be recapitulated in clinical practice in a real-world setting.

- Results from the physicians' global assessment of efficacy and tolerability will be useful in determining physician comfort level with prescribing linaclotide for their patients.

- This was a non-interventional study that lacked a placebo control; thus, the statistical analyses are descriptive and exploratory in nature.

\section{INTRODUCTION}

Irritable bowel syndrome (IBS) is a functional gastrointestinal (GI) disorder characterised by recurrent abdominal pain or discomfort and change in bowel habits. ${ }^{1}$ IBS is a common GI ailment, with global prevalence ranging from $3 \%$ to $21 \%$, depending on the diagnostic criteria. ${ }^{2}$ The prevalence of IBS in Europe is estimated at 12\%-15\%. ${ }^{3}$ IBS is subtyped based on the predominant stool pattern, and includes IBS subtype with constipation (IBS-C), diarrhoea (IBS-D), mixed stool (IBS-M) or un-subtyped (IBS-U) when stool consistency does not meet criteria for IBS-C, IBS-D or IBS-M. ${ }^{4}$ When defined by Rome III diagnostic criteria, IBS is prevalent in approximately $1 \%-29 \%$ of the general population, with IBS-C present in $1 \%-4 \% .^{5}$ Of the IBS subtypes, IBS-C is the second most 
common subtype, comprising approximately $35 \%$ of all IBS cases. ${ }^{3}$

In addition to abdominal pain and discomfort, patients with IBS-C often experience hard or lumpy stools, straining, feeling of incomplete evacuation and bloating. Moreover, IBS-C has an undue impact on quality of life, increases healthcare costs and reduces work productivity. ${ }^{67}$ Since IBS-C presents with a constellation of symptoms, therapy options have centred on symptom relief and have generally included dietary and lifestyle modifications, and over-the-counter medications such as fibre supplements and laxatives which aim to relieve constipation. However, these treatments are often ineffective and patients resort to additional therapies, which in turn drives up healthcare costs and resources, thus underscoring the need to identify efficacious treatment options for IBS-C. ${ }^{8}$

Linaclotide is a minimally absorbed 14-amino acid guanylate cyclase-C (GC-C) receptor agonist structurally related to the guanylin peptide family. ${ }^{9}$ On binding to GC-C receptors, linaclotide increases the intracellular production of cyclic guanosine monophosphate (cGMP), which in turn activates the cystic fibrosis transmembrane conductance regulator, resulting in secretion of chloride and bicarbonate into the intestinal lumen, ultimately accelerating intestinal transit. ${ }^{10}$ Linaclotide was demonstrated to increase colonic transit and reduce abdominal pain and constipation in patients with IBS-C in phase II trials. ${ }^{11}{ }^{12}$ Subsequently, the efficacy and safety of linaclotide for the treatment of IBS-C was established in two placebo-controlled phase III trials that showed improvements in IBS-C symptoms, including abdominal pain and bowel movements. ${ }^{913}$

Linaclotide was approved by the Food and Drug Administration (FDA) and European Medicines Agency in 2012 for the symptomatic treatment of adults with moderate-to-severe IBS-C. ${ }^{14}{ }^{15}$ While the efficacy and safety of linaclotide have been established in clinical trial settings, these may not depict real-life experiences. To address this need, observational studies were undertaken to evaluate the effectiveness and safety of linaclotide in real-world settings in Europe. In routine clinical practice, linaclotide has recently been shown to be effective in improving IBS-C symptoms in a post-marketing authorisation study conducted in Germany. ${ }^{16}$ Herein, we aimed to document the effectiveness and safety of linaclotide for the treatment of moderate-to-severe IBS-C in adults under real-life conditions in the Alpine region of Austria and Switzerland.

\section{METHODS}

\section{Study design}

This was a multicentre, open, observational, noninterventional study (NIS) evaluating the effectiveness and safety of linaclotide for the treatment of moderate-tosevere IBS-C in adult patients under real-life routine clinical practice conditions in Austria and Switzerland. There were no treatment groups or actions to which patients were randomly assigned. A total of 200 patients were planned for enrolment across 40 sites in each country. The study was conducted from December 2013 to March 2015 in Austria and from November 2014 to November 2015 in Switzerland.

The study comprised a 4-week treatment period commencing with visit 1 at treatment initiation and visit 2 occurring approximately 4 weeks after initiation in Austria. In Switzerland, data were collected over the course of three visits, at 0,4 and 16 weeks after treatment initiation. Linaclotide was administered per the usual therapeutic procedure of the attending physician and in accordance with the indication for the drug $(290 \mu \mathrm{g}$ once daily, taken at least $30 \mathrm{~min}$ before meals). ${ }^{15}$

All participants provided written, informed consent prior to study initiation.

\section{Participants}

Eligible patients were aged $\geq 18$ years with a diagnosis of moderate-to-severe IBS-C (diagnosed by the treating physician), characterised by clinical evidence of relevant interference of symptoms with well-being and/or daily routines at work or during leisure. The decision to treat a patient with linaclotide was made solely by the treating physician prior to inclusion in the study. Patients with known hypersensitivity to the active ingredient or any other component of linaclotide, with suspected or known GI obstruction or who were pregnant or planning to become pregnant were excluded from the study.

\section{Study assessments}

All relevant data collected during routine treatment with linaclotide were recorded in case report forms. Patient demographics and medical history were collected, including diagnosis, prior treatment and symptoms of IBS-C, comorbidities and concomitant medications.

The primary effectiveness endpoints included severity of abdominal pain and bloating, frequency of bowel movements during the week before each visit, general symptom improvement relative to pretreatment, physicians' satisfaction with linaclotide therapy, sensation of incomplete bowel evacuation, change in predominant stool consistency and physicians' global assessment of the effectiveness of linaclotide. Changes in the severity of abdominal pain and bloating were measured using an 11-point numerical rating scale (NRS; $0=$ no pain/ bloating to $10=$ worst possible pain/bloating). Physicians' satisfaction with linaclotide therapy was measured using an 11-point NRS ( $0=$ very satisfied to $10=$ totally unsatisfied). General symptom improvement and improvement in three individual symptoms-abdominal pain, bloating and constipation-were measured by patient response to simple yes/no questions asked by the physician (eg, 'Have symptoms improved over the last week compared with the time prior to therapy start?'). Frequency of bowel movements during the week before each visit, sensation 
of incomplete bowel evacuation and change in predominant stool consistency were patient-reported.

Adverse events (AEs) related to linaclotide treatment or whose relation to linaclotide treatment could not be excluded were documented. AEs assessed by the physician as not related to linaclotide treatment were not documented. Other safety measures included physicians' global assessment of the tolerability of linaclotide.

\section{Statistical analyses}

Statistical analysis was performed using SAS V.9.4 software (SAS Institute). Data were analysed using descriptive statistics and no hypotheses were pre-specified. To determine whether the pre-post changes of symptoms were statistically significant, the Wilcoxon signed-rank test was applied. Reported $\mathrm{p}$ values are two-tailed, using an alpha level of 0.05 to assess statistical significance. Missing data were imputed using the last observation carried forward method. Visit 1 and 2 efficacy data were compiled for both countries, where applicable.

\section{Patient and public involvement}

This was an observational study. Patients continued on existing medication at their own discretion. Study outcomes were scored by the patients and the data collected during this study were informed by the patients' experiences.

\section{RESULTS}

\section{Patient characteristics}

A total of 86 patients in 22 sites and 52 patients in nine sites were enrolled in Austria and Switzerland, respectively. Baseline characteristics were generally comparable between the two countries. Of the enrolled patients, 71 $(82.6 \%)$ in Austria and $40(76.9 \%)$ in Switzerland were women, and the mean age was 51 and 49 years, respectively (table 1). The mean body mass index was 24 and $23 \mathrm{~kg} / \mathrm{m}^{2}$ in each country. The average time since IBS-C diagnosis was 2.1 and 5.2 years for patients in Austria and Switzerland, respectively. At baseline, $>90 \%$ of patients in both countries reported abdominal pain (mean intensity scores of 6.0 and 5.4, respectively) and bloating (mean intensity scores of 5.8 and 5.6, respectively). Patients in both countries reported a mean of 2.1 bowel movements per week. Prior treatment for IBS-C was reported by 73 (84.9\%) patients in Austria and 49 (94.2\%) patients in Switzerland, mainly consisting of laxatives and dietary fibres, while $33(38.4 \%)$ patients in Austria and 16 $(30.8 \%)$ patients in Switzerland received concurrent IBS treatment. Concomitant diseases were reported by 35 (40.7\%) patients in Austria and 10 (19.2\%) patients in Switzerland (table 1). Collectively, baseline characteristics of the patients with IBS-C in this study were reflective of the general IBS patient population (ie, approximately $70 \%$ of IBS patients are typically women, with a high likelihood of the majority of patients being $\leq 50$ years).

Throughout the course of the study, 20 (23.3\%) patients in Austria and 17 (32.7\%) patients in Switzerland discontinued linaclotide treatment, with the main reasons for discontinuation being lack of effectiveness for $13(15.1 \%)$ patients in Austria and AEs for 10 (19.2\%) patients in Switzerland. Reasons for treatment discontinuation are summarised in table 2.

\section{Effectiveness outcomes}

Effect of linaclotide treatment on symptoms of IBS-C

Linaclotide was administered over 4 weeks in Austria and 16 weeks in Switzerland, and data from the initial 4-week treatment periods are compiled in this analysis. Of the 138 enrolled patients, data were available for 128 patients at week 4. Improvements in abdominal pain, bloating and bowel movements were observed after 4 weeks of treatment with linaclotide. From a mean intensity score of 5.8 at baseline, abdominal pain was reduced to 2.7 after 4 weeks of treatment in both countries (figure 1A; $\mathrm{p}<0.001$ vs visit $1 ; 11$-point NRS $[0=$ no pain to $10=$ worst possible pain]). In Switzerland, continued reduction in abdominal pain was observed at week 16 , with a mean intensity score of 2.5 ( $\mathrm{SD} \pm 2.0 ; \mathrm{n}=51 ; \mathrm{p}<0.0001$ vs visit 1$)$. Improvements in bloating were also seen after 4 weeks of treatment in both countries; from a baseline mean intensity score of 5.8, the bloating score was reduced to 3.1 at week 4 (figure $1 \mathrm{~B} ; \mathrm{p}<0.001$ vs visit $1 ; 11$-point NRS [0=no bloating to $10=$ worst possible bloating]), with a mean intensity score of 3.0 ( $\mathrm{SD} \pm 2.2 ; \mathrm{n}=51 ; \mathrm{p}<0.0001$ vs visit 1 ) at week 16 in Switzerland. Furthermore, the frequency of bowel movements increased from a mean of 2.1 per week at baseline to 4.5 at week 4 (figure $1 \mathrm{C} ; \mathrm{p}<0.001$ vs visit 1 ) in both countries, and to 4.7 ( $\mathrm{SD} \pm 1.6 ; \mathrm{n}=51 ; \mathrm{p}<0.0001 \mathrm{vs}$ visit 1) at week 16 in Switzerland.

Data were stratified based on patients who received prior IBS-C treatment, and improvements in IBS-C symptoms were observed within the 4-week treatment period, regardless of prior IBS-C treatment. Significant reductions from week 1 to week 4 in mean abdominal pain intensity and mean bloating intensity were seen in patients who had received laxative pretreatment and in those who had not received prior IBS-C treatment (figure 2A,B; all $\mathrm{p}<0.001$ vs visit 1$)$. Similar degrees of mean reduction in abdominal pain were seen in patients who did not and in those who did receive laxative pretreatment (both 3.1). Furthermore, the effect of concomitant laxative use with linaclotide was evaluated. Our results showed that significant reduction was achieved after 4 weeks of treatment in mean abdominal pain intensity (figure 3A; all $\mathrm{p}<0.001$ vs visit 1 ) and mean bloating intensity (figure $3 \mathrm{~B}$; all $\mathrm{p}<0.001$ vs visit 1 ), both in patients who used laxatives concomitantly with linaclotide and in those who did not. Greater symptom improvement was observed in those who did not use concomitant treatment (mean reduction in abdominal pain: 3.5 vs 1.9 ; mean reduction in bloating: 3.0 vs 1.9 ; figure $3 \mathrm{~A}, \mathrm{~B}$; all differences $\mathrm{p}<0.001$ vs visit 1 ).

\section{Patient assessment of improvement in IBS-C symptoms}

At each respective end-of-treatment period, patients were asked to indicate their sense of general improvement in 
Table 1 Patient baseline demographics and characteristics

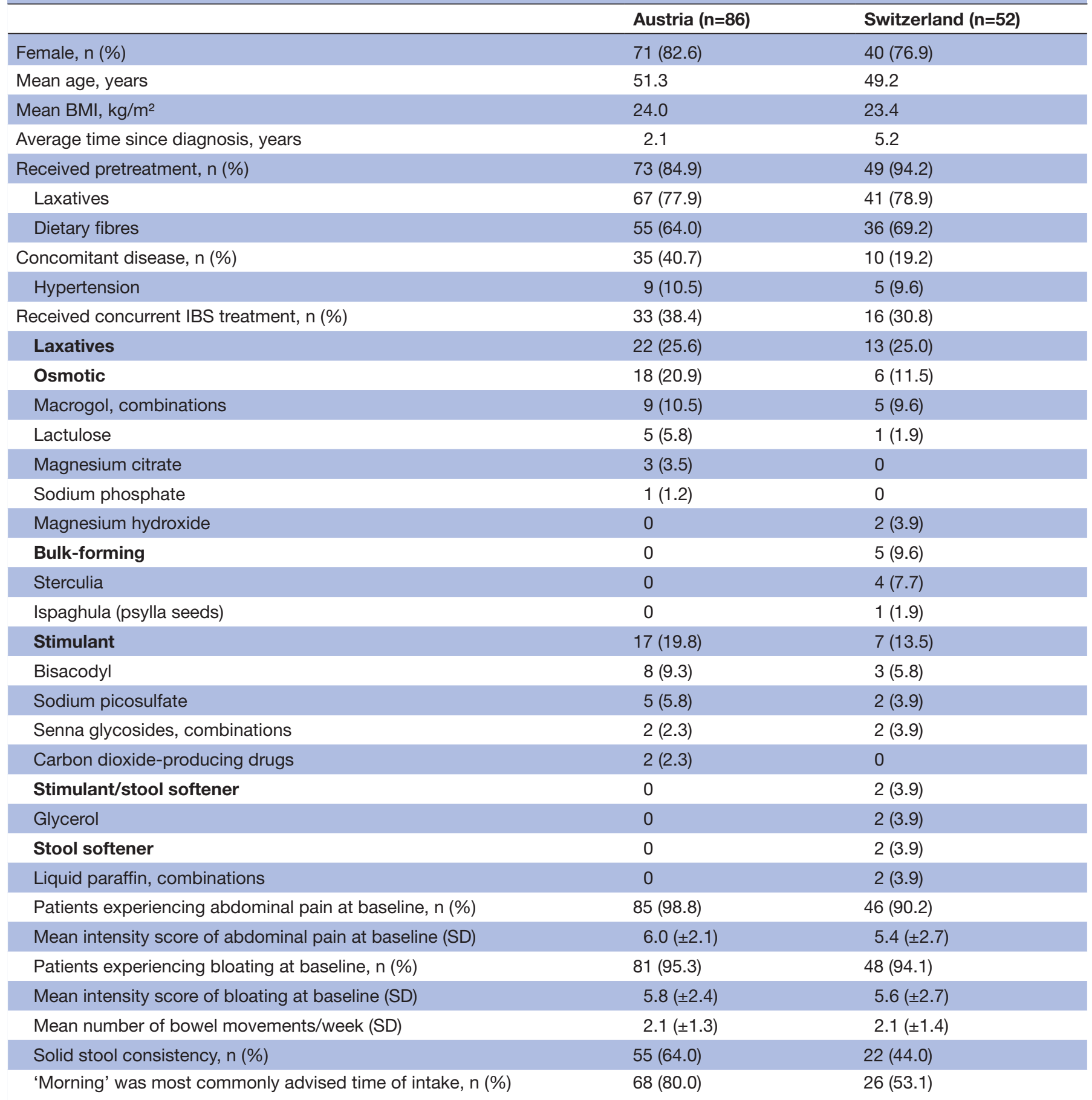

$\%$ are calculated from total number of patients providing data for that outcome. Laxatives reported by type and chemical substance. Baseline IBS symptoms were assessed during the week before start of therapy; $0=$ no pain/bloating; 10=worst pain/bloating.

$\mathrm{BMI}$, body mass index; IBS, irritable bowel syndrome.

symptoms as compared with the pretreatment period. In Austria, $74(87.1 \%)$ patients reported overall improved symptoms, among whom $56(65.9 \%)$ patients experienced improvements in abdominal pain, 60 (70.6\%) had improvements in bloating and $65(76.5 \%)$ reported improvements in constipation at visit 2 compared with baseline (figure 4). In Switzerland, 45 (88.2\%) patients reported overall improved symptoms, consisting of $38(74.5 \%)$ patients with improvements in abdominal pain, $35(68.6 \%)$ with improvements in bloating and 42 $(82.4 \%)$ reporting improvements in constipation after 16 weeks of treatment compared with baseline (figure 4).

Physician assessment of satisfaction and effectiveness of linaclotide therapy

Physicians' satisfaction with linaclotide treatment was assessed on a scale from 0 (very satisfied) to 10 (totally unsatisfied). In Austria, mean satisfaction was 2.9 (SD 
Table 2 Reasons for discontinuing linaclotide

\begin{tabular}{lcc}
\hline & $\begin{array}{l}\text { Austria } \\
(\mathbf{n = 8 6 )}\end{array}$ & $\begin{array}{l}\text { Switzerland } \\
(\mathbf{n = 5 2 )}\end{array}$ \\
\hline Discontinued patients, $\mathrm{n}(\%)$ & $20(23.3)$ & $17(32.7)$ \\
Lack of effectiveness & $13(15.1)$ & $5(9.6)$ \\
Adverse events & $8(9.3)$ & $10(19.2)$ \\
Improvement in symptoms & $5(5.8)$ & $5(9.6)$ \\
Lack of compliance & $1(1.2)$ & 0 \\
Excessive drug effect & 0 & $1(1.9)$ \\
\hline
\end{tabular}

Austria: Seven patients reported two reasons each.

Switzerland: Four patients reported two reasons each.

\pm 3.0 ; median 2.0) points after 4 weeks of treatment, indicative of 'good satisfaction', with at least $60 \%$ of the 83 total patients rated a score of $\leq 2.0$ by their treating physicians. In Switzerland, mean satisfaction was 4.6 ( $\mathrm{SD} \pm 3.2$; median 3.0) points after 16 weeks of treatment, indicative of 'moderate satisfaction', with at least $50 \%$ of the 51 total patients rated a score of $\leq 3.0$ by their treating physicians (figure 5A). Furthermore, physicians assessed the global effectiveness of linaclotide treatment at the end of the treatment periods, and at visit 2 linaclotide effectiveness was evaluated as 'excellent' in $33(38.4 \%)$ patients, 'good' in $30(34.9 \%)$ patients, 'moderate' in $14(16.3 \%)$ patients and 'poor' in $9(10.5 \%)$ patients in Austria. In Switzerland, physicians assessed linaclotide effectiveness as 'excellent' in 18 (37.5\%) patients, 'good' in 21 (43.8\%) patients and 'moderate' in $9(18.8 \%)$ patients, with the effectiveness not rated as 'poor' in any patient after 16 weeks of treatment (figure $5 \mathrm{~B}$ ).

Physicians were also asked to indicate the rationale for initiating linaclotide treatment. In Austria, linaclotide was prescribed due to low efficacy of previous medication for $39(45.4 \%)$ patients; for $3(3.5 \%)$ patients, linaclotide was prescribed due to low tolerability of previous medication; and for $52(60.5 \%)$ patients, linaclotide was a new prescription, whose treatment rationale was not a consequence of any previous medication. In Switzerland, 31 (59.6\%) patients were prescribed linaclotide due to low efficacy of previous medication, $3(5.8 \%)$ patients were prescribed linaclotide due to low tolerability of previous medication, while $20(38.5 \%)$ patients received linaclotide as a new IBS-C prescription and not due to any previous medication.

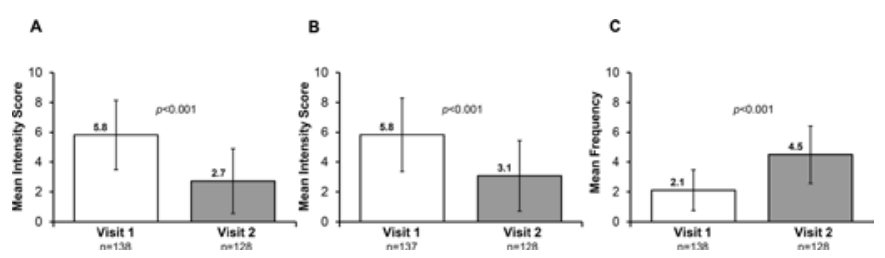

Figure 1 Effect of linaclotide treatment on $(A)$ abdominal pain, (B) bloating and $(C)$ frequency of bowel movements in all patients. Visits 1 and 2 refer to baseline and week 4 , respectively.

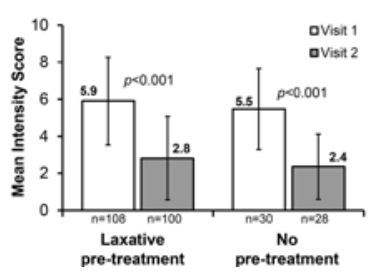

Figure 2 Effect of linaclotide treatment in patients with and without prior treatment for irritable bowel syndrome with constipation on (A) abdominal pain and (B) bloating. Visits 1 and 2 refer to baseline and week 4 , respectively.

Use of concomitant medications

Concomitant medication use was reported in 31 (36.1\%) and $13(25.0 \%)$ patients in Austria and Switzerland, respectively, with the most common being antihypertensive renin-angiotensin system agents in both countries, used by $7(8.1 \%)$ patients in Austria and $6(11.5 \%)$ patients in Switzerland. A summary of concomitant medication use by Anatomical Therapeutic Chemical classification system is presented in table 3 .

\section{Safety and tolerability}

Summary of AEs

Sixteen AEs were reported in $10(11.6 \%)$ patients in Austria after 4 weeks of treatment and 15 AEs were reported in $12(23.1 \%)$ patients in Switzerland after 16 weeks of treatment (table 4). The most common $\mathrm{AE}$ was diarrhoea, which occurred in $6(7.0 \%)$ and $8(15.4 \%)$ patients in Austria and Switzerland, respectively. Drug ineffectiveness was reported as an $\mathrm{AE}$ for $5(5.8 \%)$ patients in Austria and $2(3.9 \%)$ patients in Switzerland. AEs leading to treatment discontinuation occurred in $8(9.3 \%)$ patients in Austria and $10(19.2 \%)$ patients in Switzerland (table 2). AEs leading to dose reduction occurred in $2(2.3 \%)$ patients in Austria. The majority of AEs were mild or moderate in intensity, while severe AEs were reported in 2 (2.3\%) patients (2 events; 1 abdominal distension and 1 rectal tenesmus) in Austria and 4 $(7.7 \%)$ patients ( 5 events; 4 diarrhoea and 1 urge incontinence) in Switzerland. An AE was considered severe if the intensity of the symptoms significantly interfered with a patient's daily activities. Of all 31 reported AEs, treatment causality was confirmed for 11 AEs reported by $8(9.3 \%)$ patients in Austria and 14 (23.1\%) AEs reported by 12
A

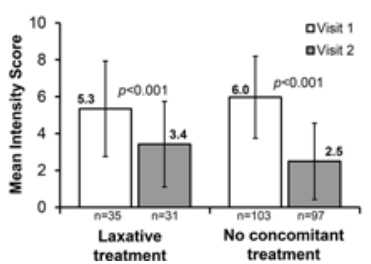

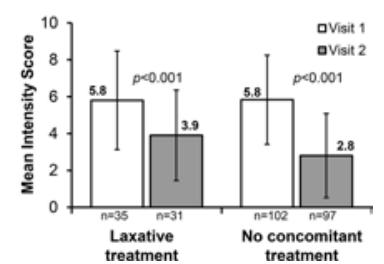

Figure 3 Effect of linaclotide treatment in patients with and without concomitant treatment for irritable bowel syndrome with constipation on (A) abdominal pain and (B) bloating. Visits 1 and 2 refer to baseline and week 4, respectively. 


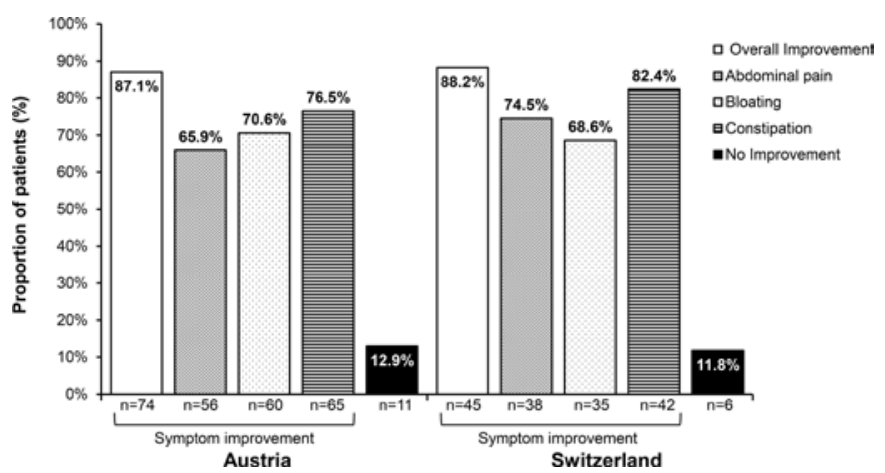

Figure 4 Proportion of patients reporting overall and individual improvement in irritable bowel syndrome with constipation symptoms at the end-of-treatment periods (week 4 in Austria and week 16 in Switzerland). Proportions are based on the number of patients with available data at respective end-of-treatment visits (Austria, $n=85$; Switzerland, $n=51)$.

patients in Switzerland. No serious AEs (ie, AEs that were life-threatening) were reported in either country over the respective 4 -week or 16 -week treatment periods.

\section{Physician assessment of linaclotide tolerability}

Treating physicians assessed the global tolerability of linaclotide treatment, and after 4 weeks of treatment linaclotide tolerability was evaluated as 'excellent' in $44(51.2 \%)$ patients, 'good' in $28(32.6 \%)$ patients, 'moderate' in $11(12.8 \%)$ patients and 'poor' in $3(3.5 \%)$ patients in Austria. In Switzerland, physicians assessed linaclotide tolerability as 'excellent' in 24 (49.0\%) patients, 'good' in $13(26.5 \%)$ patients, 'moderate' in 7 $(14.3 \%)$ patients and 'poor' in $5(10.2 \%)$ patients after 16 weeks of treatment (figure 5C).

\section{DISCUSSION}

In this NIS, the effectiveness, safety and tolerability of linaclotide were evaluated in patients with moderate-to-severe IBS-C under real-life settings in Austria and Switzerland. We observed improvements in abdominal pain, bloating and frequency of bowel movements following a 4-week treatment period in both countries, which were further
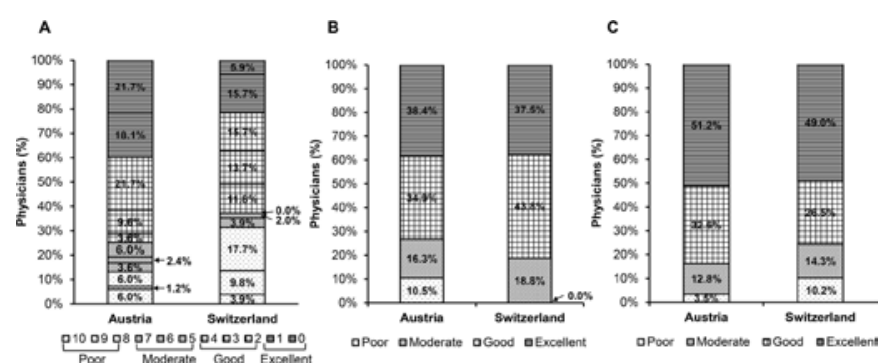

Figure 5 Physicians' assessment of (A) satisfaction, and global assessment of $(B)$ effectiveness and $(C)$ tolerability of linaclotide. Satisfaction data in (A) presented on a scale of 0 (very satisfied) to 10 (totally unsatisfied); Austria, mean $2.9 \pm 3.0$ points ('good' satisfaction); Switzerland, mean $4.6 \pm 3.2$ points ('moderate' satisfaction). sustained over 12 additional weeks in Switzerland. Significant improvements in abdominal pain and bloating were observed both in patients who received prior laxative treatment and in those who did not receive IBS-C pretreatment. However, between patients who administered laxatives concomitantly with linaclotide treatment and those who did not, the degree of reduction after 4 weeks of treatment in mean intensity score in IBS-C symptoms suggests that concomitant laxative use diminished linaclotide effect. Importantly, treating physicians rated both the effectiveness and tolerability of linaclotide as 'good' or 'excellent' for a majority of patients. Few AEs were reported in this study, none of which were serious AEs, and no new safety signals were observed throughout the study.

Abdominal pain is the major clinical manifestation of IBS and is challenging to treat. Moreover, abdominal pain is highly correlated with IBS disease severity and higher economic burden. ${ }^{17-19}$ In the present study, $>90 \%$ of all patients reported abdominal pain at baseline, with mean intensity scores of 6.0 in Austria and 5.4 in Switzerland, measured using the 11-point NRS. Clinically relevant change in the 11-point NRS for pain intensity was previously evaluated using data from 10 placebo-controlled trials that included 2724 patients with chronic pain (postherpetic neuralgia, osteoarthritis, diabetic neuropathy, chronic low back pain and fibromyalgia). ${ }^{20}$ By relating the 11-point NRS to the 7-point Patient Global Impression of Change with categories of 'much improved' and 'very much improved' used to determine a clinically relevant difference, a reduction of 2 points or $30 \%$ in the 11-point NRS was deemed clinically relevant. ${ }^{20}$ A 10-point NRS for pain intensity was evaluated in a cohort of 277 patients with IBS from the PROOF cohort, where the minimal clinically important difference was determined as 2.2 points or a $29.5 \%$ reduction in the NRS. ${ }^{19}$ Our findings showed that, collectively, the mean intensity of abdominal pain decreased from a baseline NRS level of 5.8 to 2.7 after 4 weeks of linaclotide treatment, corresponding to a 53\% reduction in abdominal pain in both countries. In Austria, the reduction in mean abdominal pain intensity score was 3.5 points $(57 \%)$ at 4 weeks, while reductions of 2.2 points (41\%) at 4 weeks and 2.9 points (53\%) after 16 weeks were observed in Switzerland. These reductions are consistent with those previously validated as clinically relevant change in pain intensity. ${ }^{19} 20$

In a recent NIS conducted in Germany, linaclotide treatment resulted in a reduction in mean pain intensity score of 1.72 points $(35 \%)$ at 4 weeks and 2.5 points $(50 \%)$ at 12 months after treatment initiation. ${ }^{16}$ Data from these European real-world studies demonstrate that improvements in abdominal pain are observed in linaclotide-treated patients within the first month of treatment initiation and are sustained throughout the respective treatment periods. Mechanistically, as a GC-C receptor agonist, linaclotide is believed to increase extracellular cGMP levels, which in turn reduces the firing of pain-sensing visceral afferent fibres, resulting in an analgesic effect, thus reducing abdominal pain. ${ }^{21}$ 
Table 3 Use of concomitant medications

\begin{tabular}{|c|c|c|}
\hline & Austria $(n=86)$ & Switzerland $(n=52)$ \\
\hline Patients receiving at least one concomitant medication, $\mathrm{n}(\%)$ & $31(36.1)$ & $13(25.0)$ \\
\hline Renin-angiotensin system agents & $7(8.1)$ & $6(11.5)$ \\
\hline Beta-blocking agents & $4(4.7)$ & $4(7.7)$ \\
\hline Lipid-modifying agents & $4(4.7)$ & $4(7.7)$ \\
\hline Analgesics & 0 & $3(5.8)$ \\
\hline Drugs for acid-related disorders & 0 & $2(3.9)$ \\
\hline
\end{tabular}

Concomitant medications reported by anatomical main group.

In addition to improvements in abdominal pain, significant improvements in bloating were also observed following 4 weeks of treatment with linaclotide. At baseline, $>94 \%$ of all patients reported bloating, and an overall reduction of 2.8 points $(47 \%)$ was observed after the 4-week treatment period in both countries, which was sustained after 16 weeks of treatment in Switzerland. Moreover, in both countries, linaclotide treatment increased the mean frequency of bowel movements from a mean of 2.1 times a week at baseline to 4.5 times a week. These observations are in line with previous animal studies which showed that linaclotide increases GI transit and fluid secretion via accumulation of intracellular cGMP in a dose-dependent manner. ${ }^{22}$

At study initiation, $>84 \%$ of patients in this study had received IBS-C pretreatment, mainly comprising laxatives

\begin{tabular}{lll}
\hline Table 4 Summary of safety & & \\
\hline & $\begin{array}{l}\text { Austria } \\
(\mathbf{n = 8 6 )}\end{array}$ & $\begin{array}{l}\text { Switzerland } \\
(\mathbf{n}=52)\end{array}$ \\
\hline Total AEs & 16 & 15 \\
Serious AEs & 0 & 0 \\
Patients with $\geq 1$ AEs, $\mathrm{n}(\%)$ & $10(11.6)$ & $12(23.1)$ \\
\hline Diarrhoea & $6(7.0)$ & $8(15.4)$ \\
Drug ineffective & $5(5.8)$ & $2(3.9)$ \\
Abdominal distension & $2(2.3)^{\star}$ & 0 \\
\hline Dizziness & 0 & $1(2.0)$ \\
Condition aggravated & $1(1.2)$ & 0 \\
Rectal tenesmus & $1(1.2)$ & 0 \\
Headache & 0 & $1(1.9)$ \\
Hot flush & 0 & $1(1.9)$ \\
Nausea & 0 & $1(1.9)$ \\
Urge incontinence & 0 & $1(1.9)$ \\
\hline
\end{tabular}

AEs recorded per preferred term using Medical Dictionary for Regulatory Activities V.18.0 (Austria) and V.18.1 (Switzerland). ${ }^{*}$ Two abdominal distension events reported for one patient. AEs, adverse events. or dietary fibres. We found that linaclotide was effective in managing symptoms of patients, regardless of prior treatment or concomitant medication use. In fact, our data found that a greater degree of improvement was observed in patients who did not use concomitant IBS-C treatment as compared with those who used concomitant laxatives (mean reduction in abdominal pain: 3.5 vs 1.9; mean reduction in bloating: 3.0 vs 1.9 ), suggesting that laxatives might interfere with the efficacy of linaclotide. Laxatives such as polyethylene glycol are often used as first-line therapy for patients with IBS-C; however, their effect on improvements in abdominal pain or bloating is inconsistent. ${ }^{123}$ A recent consensus report recommended against the co-administration of linaclotide with laxatives, especially at the beginning of treatment due to potential diarrhoeal side effects, and only suggested co-administration in cases of partial response to linaclotide. ${ }^{2}$ How concomitant laxatives may impact the efficacy of linaclotide is currently unclear. Osmotic laxatives may improve the frequency and consistency of bowel movements but have no impact on abdominal pain or bloating; moreover, some stimulant laxatives (for which there are no randomised controlled trials [RCTs] in IBS-C) may relieve chronic constipation but result in abdominal pain and cramping. ${ }^{1}$ In real-life settings, some patients may choose to add laxative treatment based on the severity of constipation, or water-binding agents may be titrated with linaclotide to gradually improve stool consistency; however, both of these strategies may inadvertently lessen the efficacy of linaclotide by binding excess fluids. Nonetheless, the present data demonstrate that linaclotide can effectively manage IBS-C symptoms irrespective of treatment history, and it does not require co-administration with other IBS-C medications, specifically laxatives.

The results of this study support the findings from pivotal phase III RCTs that evaluated the efficacy and safety of linaclotide in IBS-C. ${ }^{9132425}$ Two of the RCTs used the FDA's responder criteria of improvement of $\geq 30 \%$ from baseline in average daily worst abdominal pain score and an increase of $\geq 1$ in complete spontaneous bowel movements (CSBMs) per week. In the first double-blind, 
placebo-controlled, 26-week study of 804 participants, $49 \%$ of patients treated with linaclotide exhibited $\geq 30 \%$ improvement in abdominal pain (corresponding to a 2.1point decrease) and $48 \%$ experienced an increase of $\geq 1$ in weekly CSBMs (corresponding to a 2.2-point decrease) for at least 6 of the 12 treatment weeks. ${ }^{9}$ Moreover, linaclotide treatment resulted in increases in spontaneous bowel movements (SBMs) per week by 3.8 and CSBMs per week by 2.2. In the second pivotal multicentre, double-blind, placebo-controlled study with 800 patients with IBS-C treated over 12 weeks, linaclotide resulted in significant improvements in abdominal pain (1.9-point worst abdominal pain improvement), bloating (1.9-point improvement), SBMs per week (+3.9 frequency) and CSBMs per week (+2.3 frequency). ${ }^{13}$

Global tolerability of linaclotide treatment was assessed as 'good' or 'excellent' in $>75 \%$ of patients by their treating physicians in both countries in the current study. Moreover, physicians' satisfaction with linaclotide therapy was evaluated on a $0-10$ scale ('very satisfied' to 'totally unsatisfied'), with scores of 2.9 ('good' satisfaction) after 4 weeks in Austria and 4.6 ('moderate' satisfaction) after 16 weeks in Switzerland. In comparison, $45 \%$ and $52 \%$ of patients treated with linaclotide noted satisfaction with linaclotide in the two RCTs, while $62 \%$ of treating physicians rated the effectiveness of linaclotide as 'good' or 'excellent' in Germany in a recent NIS. ${ }^{9} 1316$ Previously, an 18-month long-term safety study demonstrated similar patient satisfaction between linaclotide-treated patients who experienced diarrhoea as compared with those who did not, and $>85 \%$ reported moderate satisfaction during the treatment period, indicating a high degree of treatment satisfaction irrespective of AEs. ${ }^{26}$

Diarrhoea has previously been reported as a potential consequence of linaclotide-mediated increase in GI transit and fluid secretion and, as such, was the most commonly reported AE during this study (7\% of patients in Austria and $15 \%$ of patients in Switzerland). All events were mild or moderate in severity. In the phase III RCTs, diarrhoea was reported by $19.5 \%$ of patients in the study by Chey $e t a l,{ }^{9}$ and by $19.7 \%$ in the study by Rao et al. ${ }^{13}$ The discrepancy in diarrhoea rates between this NIS and the previous RCTs may be due to the difference in reporting methods. Additionally, the lower incidence of adverse drug reactions reported in this NIS may be due to under-reporting by physicians of AEs already described in the summary of product characteristics. ${ }^{27}$ Finally, the impact of concomitant laxative use on diarrhoea cannot be discounted.

Treatment options for IBS-C are limited, with traditional therapies showing limited effectiveness in improving symptoms and quality of life, and only four pharmacological agents are approved for use. One such FDA-approved agent is lubiprostone, a chloride channel activator that was shown to improve IBS-C symptoms in two RCTs; however, lubiprostone is not approved for treatment in men due to limited efficacy. ${ }^{28}$ Recently, plecanatide, a GC-C receptor agonist in the same drug class as linaclotide, was approved for the treatment of IBS-C based on data from two RCTs, with a safety and efficacy profile comparable with that of linaclotide RCTs; however, no evidence from real-life clinical settings currently exists for plecanatide. ${ }^{29}{ }^{30}$ Another FDA-approved agent for IBS-C is tegaserod, a prokinetic agent that was approved in 2002 but was withdrawn from the market in 2007 due to increased cardiovascular risks. ${ }^{31}$ The FDA recently approved its reintroduction for use in adult women $<65$ years of age with IBS-C. ${ }^{32}$

Some limitations are associated with this study, which necessitate caution when interpreting the findings. The main limitations are the sample size and differing study durations between the two countries, which allowed compilation of only 4 weeks of data. Another limitation is that satisfaction with linaclotide was a physician-measured outcome, as compared with a patient-measured outcome in the clinical trials, which may lead to potential bias. The FDA's composite primary endpoint for IBS-C (responder: improvement of $\geq 30 \%$ in average daily worst abdominal pain score and increase of $\geq 1$ CSBMs from baseline, both in the same week for at least $50 \%$ of weeks assessed) was used in the two clinical trials of linaclotide to determine efficacy. ${ }^{913}$ In the present study, the lack of a composite primary endpoint may have led to inflation in the efficacy of linaclotide when compared with the clinical trials. As the diagnosis of moderate-to-severe IBS-C was determined by the treating physician without strict diagnosis criteria, selection bias may have occurred. In addition, as this was an NIS without a placebo control, the statistical analyses are descriptive and explorative, and no statistical hypotheses were pre-specified. Nevertheless, to the best of our knowledge, no real-world studies have been conducted evaluating IBS-C treatments in the Alpine region, and observational studies were thus undertaken to evaluate the effectiveness and safety of linaclotide in real-world settings in various European countries, with data recently published from Sweden, ${ }^{33}$ the $\mathrm{UK}^{34}$ and Germany. ${ }^{16}$ Our current findings suggest that linaclotide is safe and effective in reducing major symptoms of IBS-C. in routine clinical practice in Austria and Switzerland. These data support the previously reported results from two randomised phase III clinical trials that collectively demonstrate the efficacy and safety of linaclotide treatment for the management of patients with IBS-C with moderate-to-severe abdominal symptoms.

\section{Author affiliations}

${ }^{1}$ Division of Gastroenterology and Hepatology, University Hospital Zurich, Zurich, Switzerland

${ }^{2}$ Allergan Limited, Marlow, UK

${ }^{3}$ Anfomed Gesellschaft fur Angewandte Forschung in der Medizin mbH, Möhrendorf, Bayern, Germany

${ }^{4}$ Division of Gastroenterology and Hepatology, Medical University Graz, Graz, Austria

Acknowledgements The sponsor and authors would like to thank study participants and their families, study investigators, research coordinators and study staff.

Contributors DP, MF and HFH participated in the study design, trial conduct and data collection. DL and EB participated in data collection and analysis. All authors interpreted the data and participated in writing the manuscript with medical writing 
services provided by the funder. All authors read the manuscript critically and approved the final version.

Funding This study was sponsored by Allergan plc.

Competing interests Writing and editorial assistance was provided to the authors by Germaine $\mathrm{D}$. Agollah, $\mathrm{PhD}$ of Allergan. Editorial assistance was also provided to the authors by Complete HealthVizion, Inc., funded by Allergan plc, Dublin, Ireland. All authors met the ICMJE authorship criteria.

Patient consent for publication Not required.

Ethics approval The study protocols were approved by the local Institutional Review Board or Independent Ethics Committee of each centre (Austria, 26-279 ex 13/14; Switzerland, KEK-ZH-Nr.2014-0137). The study was conducted in accordance with the Declaration of Helsinki, applicable local laws and regulations and International Conference on Harmonisation E6 Good Clinical Practice guidelines.

Provenance and peer review Not commissioned; externally peer reviewed. Data availability statement Data reported in this manuscript are available within the article.

Open access This is an open access article distributed in accordance with the Creative Commons Attribution Non Commercial (CC BY-NC 4.0) license, which permits others to distribute, remix, adapt, build upon this work non-commercially, and license their derivative works on different terms, provided the original work is properly cited, appropriate credit is given, any changes made indicated, and the use is non-commercial. See: http://creativecommons.org/licenses/by-nc/4.0/.

ORCID iD

Daniel Pohl http://orcid.org/0000-0002-0855-1152

\section{REFERENCES}

1 Chey WD, Kurlander J, Eswaran S. Irritable bowel syndrome: a clinical review. JAMA 2015;313:949-58.

2 Rey E, Mearin F, Alcedo J, et al. Optimizing the use of linaclotide in patients with constipation-predominant irritable bowel syndrome: an expert consensus report. Adv Ther 2017;34:587-98.

3 Lovell RM, Ford AC. Global prevalence of and risk factors for irritable bowel syndrome: a meta-analysis. Clin Gastroenterol Hepatol 2012;10:712-21.

4 Longstreth GF, Thompson WG, Chey WD, et al. Functional bowel disorders. Gastroenterology 2006;130:1480-91.

5 Oshima T, Miwa H. Epidemiology of functional gastrointestinal disorders in Japan and in the world. J Neurogastroenterol Motil 2015;21:320-9.

6 Paré P, Gray J, Lam S, et al. Health-related quality of life, work productivity, and health care resource utilization of subjects with irritable bowel syndrome: baseline results from logic (longitudinal outcomes study of gastrointestinal symptoms in Canada), a naturalistic study. Clin Ther 2006;28:1726-35.

7 Mayer EA. Clinical practice. irritable bowel syndrome. N Engl J Med 2008;358:1692-9.

8 Guerin A, Carson RT, Lewis B, et al. The economic burden of treatment failure amongst patients with irritable bowel syndrome with constipation or chronic constipation: a retrospective analysis of a Medicaid population. J Med Econ 2014;17:577-86.

9 Chey WD, Lembo AJ, Lavins BJ, et al. Linaclotide for irritable bowel syndrome with constipation: a 26-week, randomized, doubleblind, placebo-controlled trial to evaluate efficacy and safety. Am J Gastroenterol 2012;107:1702-12.

10 Bryant AP, Busby RW, Bartolini WP, et al. Linaclotide is a potent and selective guanylate cyclase $\mathrm{C}$ agonist that elicits pharmacological effects locally in the gastrointestinal tract. Life Sci 2010;86:760-5.

11 Johnston JM, Kurtz CB, MacDougall JE, et al. Linaclotide improves abdominal pain and bowel habits in a phase Ilb study of patients with irritable bowel syndrome with constipation. Gastroenterology 2010;139:1877-86.

12 Andresen V, Camilleri M, Busciglio IA, et al. Effect of 5 days linaclotide on transit and bowel function in females with constipationpredominant irritable bowel syndrome. Gastroenterology 2007;133:761-8.

13 Rao S, Lembo AJ, Shiff SJ, et al. A 12-week, randomized, controlled trial with a 4-week randomized withdrawal period to evaluate the efficacy and safety of linaclotide in irritable bowel syndrome with constipation. Am J Gastroenterol 2012;107:1714-24.

14 US Food and Drug Administration. Linzess. highlights of prescribing information, 2012. Available: https://www.accessdata.fda.gov/ drugsatfda_docs/label/2012/202811s000lbl.pdf [Accessed 12 Jun 2016].

15 European Medicines Agency. Summary of product characteristics: Constella (linaclotide), 2012. Available: http://www.ema.europa.eu/ docs/en_GB/document_library/EPAR_-_Product_Information/human/ 002490/WC500135622.pdf [Accessed 23 Apr 2019].

16 Andresen V, Miehlke S, Beck E, et al. Efficacy and tolerability of linaclotide in the treatment of irritable bowel syndrome with constipation in a real-world setting - results from a German noninterventional study. Z Gastroenterol 2018;56:738-44.

17 Lembo A, Ameen VZ, Drossman DA. Irritable bowel syndrome: toward an understanding of severity. Clin Gastroenterol Hepatol 2005;3:717-25.

18 Spiegel B, Strickland A, Naliboff BD, et al. Predictors of patientassessed illness severity in irritable bowel syndrome. Am J Gastroenterol 2008;103:2536-43.

19 Spiegel B, Bolus R, Harris LA, et al. Measuring irritable bowel syndrome patient-reported outcomes with an abdominal pain numeric rating scale. Aliment Pharmacol Ther 2009;30:1159-70.

20 Farrar JT, Young JP, LaMoreaux L, et al. Clinical importance of changes in chronic pain intensity measured on an 11-point numerical pain rating scale. Pain 2001;94:149-58.

21 Castro J, Harrington AM, Hughes PA, et al. Linaclotide inhibits colonic nociceptors and relieves abdominal pain via guanylate cyclase-C and extracellular cyclic guanosine 3',5'-monophosphate. Gastroenterology 2013;145:1334-46. e1-11.

22 Busby RW, Bryant AP, Bartolini WP, et al. Linaclotide, through activation of guanylate cyclase $\mathrm{C}$, acts locally in the gastrointestinal tract to elicit enhanced intestinal secretion and transit. Eur $J$ Pharmacol 2010;649:328-35.

23 Chapman RW, Stanghellini V, Geraint M, et al. Randomized clinical trial: macrogol/PEG 3350 plus electrolytes for treatment of patients with constipation associated with irritable bowel syndrome. Am J Gastroenterol 2013;108:1508-15.

24 Yang Y, Fang J, Guo X, et al. Linaclotide in irritable bowel syndrome with constipation: a phase 3 randomized trial in China and other regions. J Gastroenterol Hepatol 2018;33:980-9.

25 Fukudo S, Miwa H, Nakajima A, et al. A randomized controlled and long-term linaclotide study of irritable bowel syndrome with constipation patients in Japan. Neurogastroenterol Motil 2018;30:e13444.

26 Chey W, Shiff S, Schneier $\mathrm{H}$, et al. Two years on linaclotide: tolerability and treatment satisfaction in IBS-C patients with and without diarrhea: presidential poster. Am J Gastroenterol 2014;109:S530.

27 Lopez-Gonzalez E, Herdeiro MT, Figueiras A. Determinants of underreporting of adverse drug reactions: a systematic review. Drug Saf 2009;32:19-31

28 Drossman DA, Chey WD, Johanson JF, et al. Clinical trial: lubiprostone in patients with constipation-associated irritable bowel syndrome-results of two randomized, placebo-controlled studies. Aliment Pharmacol Ther 2009;29:329-41.

29 US Food and Drug Administration. Highlights of prescribing information: TRULANCE (plecanatide), 2018. Available: https://www. accessdata.fda.gov/drugsatfda_docs/label/2018/208745s001lbl.pdf [Accessed Jan 2018].

30 Shah ED, Kim HM, Schoenfeld P. Efficacy and tolerability of guanylate cyclase-C agonists for irritable bowel syndrome with constipation and chronic idiopathic constipation: a systematic review and meta-analysis. Am J Gastroenterol 2018;113:329-38.

31 US Food and Drug Administration. Postmarket drug safety information for patients and providers: Zelnorm (tegaserod maleate) information, 2018. Available: http://www.fda.gov/Drugs/DrugSafety/ PostmarketDrugSafetylnformationforPatientsandProviders/ ucm103223.htm [Accessed 23 Apr 2019].

32 US Food and Drug Administration. Zelnorm highlights of prescribing information, 2019. Available: https://www.accessdata.fda.gov/ drugsatfda_docs/label/2019/0212000rig1s015lbl.pdf [Accessed Apr 2019].

33 Lindfors P, Bytzer P, Hausken T, et al. Linaklotid-behandling vid Irritable Bowel Syndrome med förstoppning: En prospektiv, multicenter, icke-interventions, fas IV studie i Norden (PROCEED studien) [abstract]. Svenska Gastrodagarna 2018;25.

34 Yiannakou Y, Agrawal A, Allen PB, et al. UK clinical experience up to 52 weeks with linaclotide for irritable bowel syndrome with constipation. Therap Adv Gastroenterol 2018;11:175628481879879. 